\title{
Precipitation classification at mid-latitudes in terms of drop size distribution parameters
}

\author{
C. Caracciolo ${ }^{1}$, F. Porcù ${ }^{1}$, and F. Prodi ${ }^{1,2}$ \\ ${ }^{1}$ Department of Physics, University of Ferrara, Italy \\ ${ }^{2}$ Institute of Atmospheric Sciences and Climate of the Italian National Research Council (ISAC-CNR), Bologna, Italy
}

Received: 2 August 2007 - Revised: 14 January 2008 - Accepted: 29 January 2008 - Published: 9 April 2008

\begin{abstract}
The drop size distribution (DSD) is a fundamental property of rainfall because the shape of the distribution reflects the physics of rain formation processes. Given the lack of studies on the DSD at mid-latitudes, the present work focuses on the microphysical characterization of precipitation events occurring in Italy, using two different types of disdrometer. A large number of different rain events was collected: they underwent microphysical analysis by computing the Z-R relationships, observing the average DSDs and DSD parameters, fitting the real distribution for different rainfall rate categories and applying convective (C) - stratiform (S) discrimination algorithms. A general agreement with past works at mid-latitudes is found both in the Z-R relationship and in DSD parameters. The rain distribution is well described by a gamma DSD and only in some cases (especially the light rain events) by an exponential DSD. Marked differences are observed in DSD parameters and Z-R relationships between $\mathrm{C}$ and $\mathrm{S}$ episodes. The use of disdrometers for areas covered by multiparametric radar is suggested and will be performed in the near future.
\end{abstract}

\section{Introduction}

One of the most complete descriptions of rain is given by its DSD. The spatial and temporal variability of DSD reflects variations in the relative importance of the microphysical processes inside clouds (e.g. coalescence, break-up, evaporation), which may be related to differences in the observed ground rainfall integral variables and DSD parameters.

The problem of estimating precipitation dimensional parameters has attracted renewed interest over recent years for two main reasons. One the one hand, more complete infor-

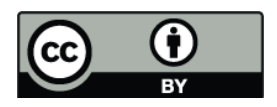

Correspondence to: C. Caracciolo (caracciolo@fe.infn.it) mation on the precipitation characteristics (than the simple instantaneous rainfall rate) is needed for radar calibration or satellite sensor interpretation, in the frame of super-sites designed for ground validation and calibration (Wolff et al., 2005). On the other hand, new instruments have been proposed (based on a wide variety of physical principles, e.g. electromechanical impact, Doppler effect, optical extinction) for more accurate measurements and disdrometer comparisons have been performed during experimental campaigns (e.g. Krajewski et al., 2006).

The discrimination between $\mathrm{C}$ and $\mathrm{S}$ precipitation is of particular relevance, even if only a few works have focused on mid-latitude continental rain (e.g. Waldvogel, 1974; Ulbrich, 1983; Zawadski et al., 1994), while more recently many authors have analyzed tropical oceanic case studies (e.g. Tokay and Short, 1996; Testud et al., 2001). There is also a lack of studies performed in the Mediterranean area. To deal with the specific characteristics of continental midlatitude rain, Caracciolo et al. (2006a) have proposed a new $\mathrm{C} / \mathrm{S}$ discrimination algorithm, that is more suitable than the tropical ones.

Classically, DSD is measured by an electromechanical impact disdrometer called Joss-Waldvogel (hereinafter JW) (Joss and Waldvogel, 1967). A new device named Pludix (Prodi et al., 2000), an X-band rain-gauge/disdrometer, has recently shown good performances, complementing optical and impact devices (Caracciolo et al., 2006b).

The present work reports on the analysis of the drop size characteristics of precipitation in Italy, using JW and Pludix. Disdrometric data measured during rainfall measuring campaigns are collected and analyzed, allowing a rain classification and characterization in terms of dimensional parameters. The work brings together the most extensive database in Italy up to now, representing regions with different rainfall regimes: Alpine foothills (Turin), Po Valley (Bologna and Ferrara), central Italy (Florence) and southern Italy and Islands. 
Table 1. The Italian databases used in the analysis.

\begin{tabular}{|c|c|c|c|c|c|}
\hline Location & Lat-Lon coordinates & Instrument & Analysis period & Rain events & Rain minutes \\
\hline 1 FERRARA & $44^{\circ} 48^{\prime} \mathrm{N} 11^{\circ} 39^{\prime} \mathrm{E}$ & JW & 2001/11- 2004/06 & 41 & $1872^{\prime}$ \\
\hline \multirow[t]{2}{*}{2 BOLOGNA } & $44^{\circ} 31^{\prime} \mathrm{N} 11^{\circ} 20^{\prime} \mathrm{E}$ and & Pludix & $\begin{array}{c}2006 / 09-2006 / 10 \text { and } \\
2005 / 07-2006 / 09\end{array}$ & 52 & $15471^{\prime}$ \\
\hline & $44^{\circ} 39^{\prime} \mathrm{N} 11^{\circ} 38^{\prime} \mathrm{E}$ & & & & \\
\hline 3 FLORENCE & $43^{\circ} 39^{\prime} \mathrm{N} \quad 11^{\circ} 11^{\prime} \mathrm{E}$ & JW Pludix & $2006 / 09-2007 / 05$ & 51 & $25048^{\prime}$ JW 29026' Pludix \\
\hline 4 TURIN & $45^{\circ} 4^{\prime} \mathrm{N} \quad 6^{\circ} 41^{\prime} \mathrm{E}$ & Pludix & 2006/09-2007/06 & 29 & $15366^{\prime}$ \\
\hline 5 SOUTH ITALY & $37^{\circ} 6^{\prime} \mathrm{N} \quad 13^{\circ} 56^{\prime} \mathrm{E}$ and $40^{\circ} 35^{\prime} \mathrm{N} 8^{\circ} 22^{\prime} \mathrm{E}$ and $40^{\circ} 10^{\prime} \mathrm{N} \quad 16^{\circ} 31^{\prime} \mathrm{E}$ & Pludix & 2003/10-2005/04 & 82 & $19764^{\prime}$ \\
\hline
\end{tabular}

1: Department of Physics - University of Ferrara - Ferrara

2: Institute of Atmospheric Sciences and Climate - National Research Council (ISAC-CNR) and S. Pietro Capofiume - Bologna

3: Montepaldi (San Casciano in Val di Pesa) - Florence

4: Bardonecchia - Turin

5: South Italy: Licata (Agrigento), Surigheddu (Sassari), Rotondella (Matera)

\section{Data and experimental set up}

Experimental sites in southern and northern Italy have been established (see Table 1). They are equipped with a classical JW disdrometer and/or an X-band pluvio-disdrometer (Pludix), all with sampling time of one minute.

There are three different sources of error affecting the measurement of small drops with the JW disdrometer: wind, acoustic noise from the surroundings, and the ringing of the styrofoam cone when hit by large drops (known as disdrometer dead time). The influences of the first two sources are reduced to a minimum by a proper installation of the transducer; no correction is here applied to the DSD to account for the dead time problem. No on-site calibration is performed on the disdrometer, as the sensor head used was new and calibrated by the manufacturer.

The JW data consist of number of raindrops $n_{i}$ of diameter $D_{i}$ in 20 size categories from $0.31 \mathrm{~mm}$ to $5.6 \mathrm{~mm}$. The computation of the DSD $\left(\mathrm{mm}^{-1} \mathrm{~m}^{-3}\right)$ and of the rainfall rate $R$ $\left(\mathrm{mm} \mathrm{h}^{-1}\right)$ from these data involves a simple summation over drop size classes.

Pludix is a low-power X-band $(9.5 \mathrm{GHz})$, continuous wave $(\mathrm{CW})$ radar, detecting the electromagnetic radiation backscattered by falling hydrometeors (Prodi et al., 2000; Caracciolo et al., 2006b). The instrument suffers from some problems, also common to small CW bi-static Doppler radars, including the following (Doviak and Zrnic, 1993): run-off and vibration of raindrops on the radome; variable absorption losses due to water on the radome; effect of horizontal winds on DSD retrieval; sampling errors caused by the non-uniform response from different locations in the measurement volume. For Pludix, these problems are attenuated or corrected as follows: a microwave transparent sponge is set on the elliptical base radome to avoid vibrations; the bellshaped form of the Pludix radome avoids water deposition of the radome; no correction for wind effects is carried out on the Pludix; the Pludix measurement volume is defined by an average antenna gain.
The data collected here are contaminated by ground noise signals that are present at the lowest frequencies $(<50 \mathrm{~Hz})$, due to interferences of a physical nature. The noise removal is accomplished by detecting a characteristic noise spectrum during a non-rainy day and subtracting it from the measured spectrum when precipitation is detected.

The power signal is inverted to generate the DSD $\left(\mathrm{mm}^{-1} \mathrm{~m}^{-3}\right)$. The actual rainfall rate $R\left(\mathrm{~mm} \mathrm{~h}^{-1}\right)$ is an indirect product. The drops are classified in constant size intervals $(0.3 \mathrm{~mm})$; the diameter range varies in 21 size categories from 0.8 to $7.0 \mathrm{~mm}$.

The two disdrometers provide, during the different experimental campaigns in a wide sample of Italian climate areas (see Table 1), a wide and unique dataset of DSD for various rainfall events, allowing a classification of the precipitation (into $\mathrm{C}$ and $\mathrm{S}$ ) and a microphysical characterization of the rain episodes.

\section{Methodology}

To parameterize the DSD, each observed 1-minute spectrum of each event is fitted by an exponential and a gamma DSD.

The parameters of an exponential distribution of type:

$N(D)=N_{0} \exp (-\Lambda D)\left(\mathrm{mm}^{-1} \mathrm{~m}^{-3}\right)$

where $\mathrm{N}_{0}\left(\mathrm{~mm}^{-1} \mathrm{~m}^{-3}\right)$ is the intercept and $\Lambda\left(\mathrm{mm}^{-1}\right)$ the slope parameter, are computed following Waldvogel (1974).

Marshall and Palmer (1948), hereinafter MP, have found a constant value of $\mathrm{N}_{0}=8000 \mathrm{~mm}^{-1} \mathrm{~m}^{-3}$ for widespread midlatitude rain.

The parameters of a gamma distribution of type:

$N(D)=N_{0} D^{m} \exp (-\Lambda D)\left(\mathrm{mm}^{-1} \mathrm{~m}^{-3}\right)$

where $\mathrm{m}$ is the shape, $\mathrm{N}_{0}$ the intercept $\left(\mathrm{mm}^{-1-m} \mathrm{~m}^{-3}\right)$ and $\Lambda$ the slope parameter $\left(\mathrm{mm}^{-1}\right)$ (Ulbrich, 1983), are computed following the classical method of moments of Tokay and Short (1996), hereinafter TS. 
(a)

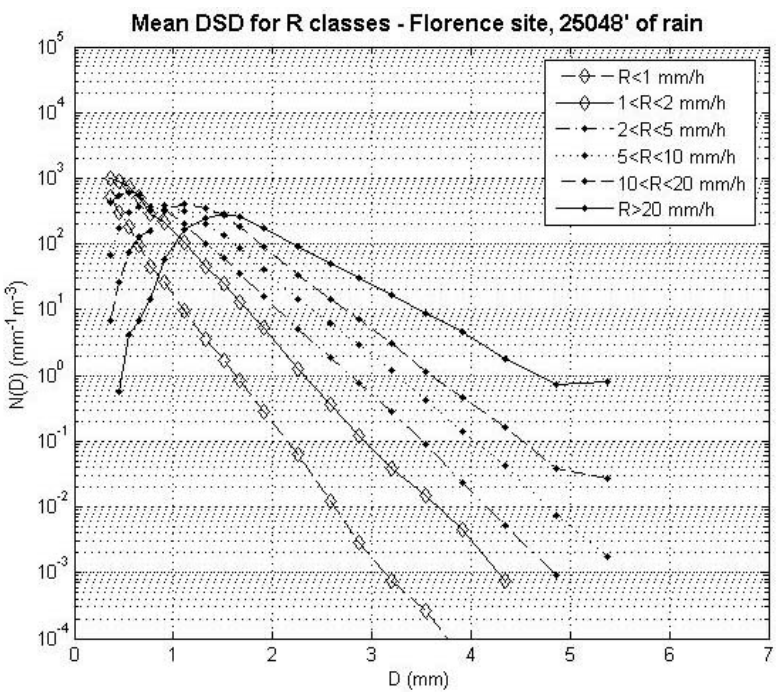

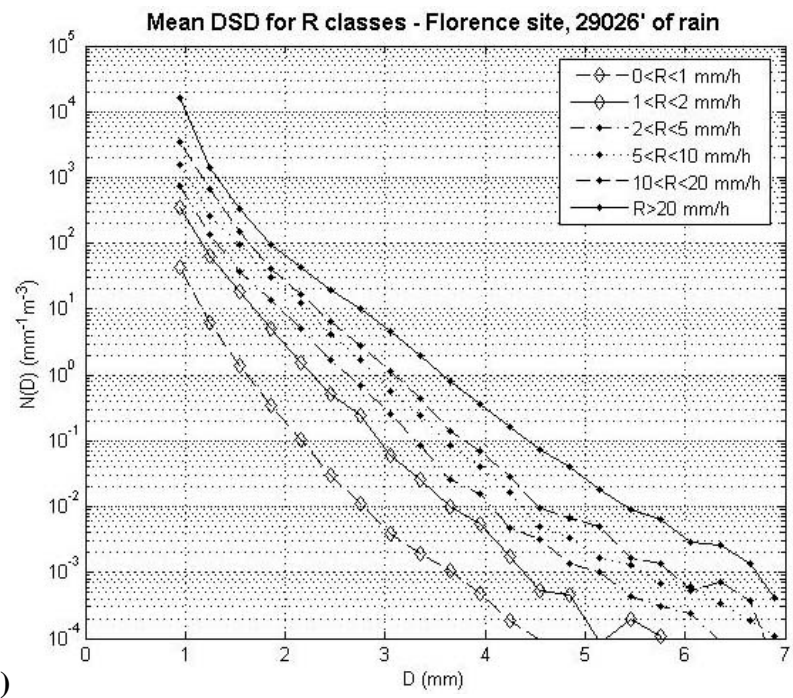

Fig. 1. Average observed DSDs for the Florence database: JW disdrometer (a) and Pludix disdrometer (b), for six rainfall rate categories.

The disdrometer data are first used to detect (threshold in rainfall rate $>0.2 \mathrm{~mm} / \mathrm{h}$ with at least $10 \mathrm{~min}$ of continuous rain) the rain episodes. A global microphysical analysis (results shown in Sect. 4) is successively performed by:

1. analyzing the average DSDs and DSD parameters from the 1-min spectra, classified into six categories of different rainfall rate intensities for each database;

2. applying two $\mathrm{C} / \mathrm{S}$ discrimination algorithms. The first is a refinement of the gamma DSD-based method proposed by Caracciolo et al. (2006a) on JW data in Ferrara, while the second is implemented observing the Pludix 1-minute exponential DSD parameters for each rain event. The two methods are described in Section 4.2. A complete statistical study is presented, applying the algorithms to each database, to detect the $\mathrm{S}$ and $\mathrm{C}$ minutes and identify their peculiar characteristics in terms of DSD parameters;

3. computing the Z-R relationship by a linear regression method for each 1-minute spectrum in each database.

\section{Experimental results}

4.1 Shape and parameters of the drop size distribution for rain categories

Figure 1 shows the observed DSDs for the Florence database, taken as representative, for the two instruments, averaged for six rainfall rate categories: very light $\left(R<1 \mathrm{~mm} \mathrm{~h}^{-1}\right)$, light $\left(1 \leq R<2 \mathrm{~mm} \mathrm{~h}^{-1}\right)$, moderate $\left(2 \leq R<5 \mathrm{~mm} \mathrm{~h}^{-1}\right)$, heavy $\left(5 \leq R<10 \mathrm{~mm} \mathrm{~h}^{-1}\right)$, very heavy $\left(10 \leq R<20 \mathrm{~mm} \mathrm{~h}^{-1}\right)$, extreme $\left(R \geq 20 \mathrm{~mm} \mathrm{~h}^{-1}\right)$. Each 1-min DSD is classified into one of the six categories, and subsequently the average is performed for each category over all events in each database.

Looking at Fig. 1a (JW disdrometer), the DSDs are always concave downward. This behavior is partly derived from the lack of small drops due to the JW disdrometer dead time problem, highlighted by the sharp decrease in the number of raindrops for diameters lower than $0.6 \mathrm{~mm}$. In addition, for heavy rainfall-rates, the cone water coating may play a role. As the rainfall rate threshold increases, the DSD shifts toward large diameters and is very flat. In the lightprecipitation categories, the DSDs have an almost exponential shape and the $\mathrm{N}_{0}$ values are not far from the value of $8000 \mathrm{~mm}^{-1} \mathrm{~m}^{-3}$, in agreement with the MP findings. Otherwise, the heavy rain events are better parameterized by a gamma DSD. The heavy rain events are, therefore, characterized by large $\mathrm{m}$ values, caused by the strong downward concavity, while the gamma $\Lambda$ and $\mathrm{N}_{0}$ values generally have small values (see Table 2). Furthermore, as the rain threshold increases, the exponential $\mathrm{N}_{0}$ and $\Lambda$ parameters generally tend to decrease.

Looking at Fig. 1b, it is noted that, when using the Pludix, the DSDs are always exponential or slightly concave upward. Therefore, instrumental effects (e.g. the lower Pludix drop diameter threshold of $0.8 \mathrm{~mm}$ ) may affect the rainfall characterization of the events. The rise in the number of drops as the rain threshold increases involves all the diameter classes considered by the instrument (the $\Lambda$ parameter it is quite constant, while $\mathrm{N}_{0}$ increases by about 2-3 orders of magnitudes, here not shown). Such findings are used to provide the new C/S discrimination algorithm described in Section 4.2. The exponential fit works better, especially for the light and very light rain categories. The upper Pludix drop diameter threshold of $7.0 \mathrm{~mm}$ provides more significant DSD values for heavy rains, even if at mid-latitudes drops larger 
Table 2. Averaged gamma (shape $\mathrm{m}$, intercept $\mathrm{N}_{0}$, slope $\Lambda$ ) DSD parameters and exponential (intercept $\mathrm{N}_{0}$ and slope $\Lambda$ ) DSD parameters computed with the method of moments (TS) and with the Waldvogel (1974) method, respectively, for six rainfall rate categories for the Florence and Ferrara databases (JW disdrometer).

\begin{tabular}{|c|c|c|c|c|c|}
\hline \multicolumn{6}{|c|}{ JW - FLORENCE - 25048' OF RAIN } \\
\hline$R\left[\mathrm{~mm} \mathrm{~h}^{-1}\right]$ & $<\mathrm{N}_{0}>\left[\mathrm{mm}^{-1-m} \mathrm{~m}^{-3}\right]$ & $<\Lambda>\left[\mathrm{mm}^{-1}\right]$ & $<\mathrm{m}>[-]$ & $<\mathrm{N}_{0}>\left[\mathrm{mm}^{-1} \mathrm{~m}^{-3}\right]$ & $<\Lambda>\left[\mathrm{mm}^{-1}\right]$ \\
\hline $0-1$ & $1.19 \cdot 10^{16}$ & 13.49 & 7.79 & $9.98 \cdot 10^{3}$ & 8.38 \\
\hline $1-2$ & $6.43 \cdot 10^{15}$ & 8.82 & 5.39 & $1.32 \cdot 10^{4}$ & 4.29 \\
\hline $2-5$ & $6.03 \cdot 10^{11}$ & 7.29 & 5.49 & $1.04 \cdot 10^{4}$ & 3.66 \\
\hline $5-10$ & $3.39 \cdot 10^{10}$ & 7.17 & 7.04 & $9.80 \cdot 10^{3}$ & 3.43 \\
\hline $10-20$ & $2.18 \cdot 10^{10}$ & 8.17 & 10.08 & $1.16 \cdot 10^{4}$ & 2.89 \\
\hline$\geq 20$ & $8.54 \cdot 10^{7}$ & 6.03 & 9.39 & $6.41 \cdot 10^{3}$ & 2.69 \\
\hline \multicolumn{6}{|c|}{ JW - FERRARA - 1872' OF RAIN } \\
\hline $0-1$ & $1.98 \cdot 10^{14}$ & 15.86 & 11.75 & $5.05 \cdot 10^{3}$ & 4.33 \\
\hline $1-2$ & $1.64 \cdot 10^{11}$ & 9.52 & 9.13 & $4.99 \cdot 10^{3}$ & 3.36 \\
\hline $2-5$ & $2.69 \cdot 10^{11}$ & 9.11 & 9.75 & $6.83 \cdot 10^{3}$ & 3.21 \\
\hline $5-10$ & $1.89 \cdot 10^{9}$ & 8.14 & 10.03 & $5.89 \cdot 10^{3}$ & 2.63 \\
\hline $10-20$ & $1.08 \cdot 10^{7}$ & 7.15 & 10.88 & $3.86 \cdot 10^{3}$ & 1.93 \\
\hline$\geq 20$ & $3.09 \cdot 10^{5}$ & 4.93 & 9.73 & $2.06 \cdot 10^{3}$ & 1.52 \\
\hline
\end{tabular}

than 5-6 mm diameter do not contribute significantly to the rainfall rate.

\subsection{Convective - stratiform discrimination}

The classical $\mathrm{C} / \mathrm{S}$ discrimination algorithms fail at these latitudes (see e.g. Caracciolo et al., 2006a). Two C/S discrimination algorithms are applied. The first is a refinement of the $\mathrm{C} / \mathrm{S}$ discrimination algorithm proposed by Caracciolo et al. (2006a) using a JW installed in Ferrara. This method consists of two classification steps. In Caracciolo et al. (2006a) the classification into $\mathrm{C}$ or $\mathrm{S}$ precipitation was first performed by considering a threshold in both rain and radar reflectivity: if $\mathrm{R}$ is greater than $10 \mathrm{~mm} \mathrm{~h}^{-1}$, the spectra are considered $\mathrm{C}$. When $R<10 \mathrm{~mm} \mathrm{~h}^{-1}$, a threshold in reflectivity is imposed to discriminate between the two categories: $\mathrm{Z}>38 \mathrm{dBZ} \mathrm{C}$ and $\mathrm{Z}<38 \mathrm{dBZ}$ S. However, these criteria are more suitable to detect with greater accuracy heavy convection and lightmoderate $S$ rains; they do not take into account the weak convection as well as the strong aggregation (Waldvogel, 1974) often characteristic of S spectra.

Subsequently, the investigation moved on to the behavior of a key parameter derived from the knowledge of two gamma DSD parameters ( $m$ and $\Lambda$ ), the peak (or modal) diameter $D_{p}$ defined as:

$D_{p}=m / \Lambda(\mathrm{mm})$

The peak diameter was used to discriminate the two precipitation types. Analyzing the 1-minute time evolution of the peak diameter it was found that in a $(\Lambda, \mathrm{m})$ diagram the line $(1.635 \Lambda-\mathrm{m}=1)$ allows discrimination into the two different regimes, with $\mathrm{S}$ spectra characterized by lower $D_{p}$ values with respect to the $\mathrm{C}$ ones.
Using the Florence JW data, the method is refined. Only the first classification step is refined, which has implications for the second step. The new C/S discrimination is based on four criteria, to take into account also shallow $\mathrm{C}$ and heavy $\mathrm{S}$ rains:

$$
\begin{aligned}
& \text { - if } R<10 \mathrm{~mm} \mathrm{~h}^{-1} \text { and } \mathrm{Z}<38 \mathrm{dBZ} \text { : } \mathrm{S} \text { rain } \\
& \text { - if } R>10 \mathrm{~mm} \mathrm{~h}^{-1} \text { and } \mathrm{Z}<38 \mathrm{dBZ} \text { : heavy } \mathrm{S} \\
& \text { - if } R \geq 10 \mathrm{~mm} \mathrm{~h}^{-1} \text { and } \mathrm{Z} \geq 38 \mathrm{dBZ}: \mathrm{C} \\
& \text { - if } R<10 \mathrm{~mm} \mathrm{~h}^{-1} \text { and } \mathrm{Z}>38 \mathrm{dBZ} \text { : shallow C }
\end{aligned}
$$

Applying these criteria, a new discrimination (between $\mathrm{C} /$ shallowC and $\mathrm{S} /$ heavyS spectra) line $(1.635 \Lambda-\mathrm{m}=2)$ is identified in the $(\Lambda, \mathrm{m})$ diagram (see Fig. 2a). Keeping $\mathrm{m}$ constant, the $\mathrm{S}$ spectra have $\Lambda$ values greater than the $\mathrm{C}$ ones, meaning that the $\mathrm{S}$ spectra are characterized by many small drops compared to $\mathrm{C}$ spectra. Moreover, keeping $\Lambda$ constant, the $\mathrm{C}$ spectra have $\mathrm{m}$ values greater than the $\mathrm{S}$ ones, indicating a more marked downward concavity, confirming the trend found in Fig. 1a.

Taking into account the results found in Sect. 4.1 (Fig. 1b), a second $\mathrm{C} / \mathrm{S}$ discrimination algorithm is proposed, using Pludix data.

TS have found that values of $R<2.0 \mathrm{~mm} \mathrm{~h}^{-1}$ are representative of S spectra (which lead to significant rain accumulation), while values of $R>10 \mathrm{~mm} \mathrm{~h}^{-1}$ are representative of $\mathrm{C}$ ones (relatively short in duration and highly fluctuating). The range $2-10 \mathrm{~mm} \mathrm{~h}^{-1}$ is difficult to interprete: this range can witness the occurrence of spectra of shallow convection as well as heavy $\mathrm{S}$ spectra characterized at the ground by the 
presence of large drops, formed from strong mechanisms of aggregation in clouds.

From the analysis of Pludix exponential DSD parameters for all Italian databases, it is found that changing from $\mathrm{S}$ (with $R<2 \mathrm{~mm} \mathrm{~h}^{-1}$ ) to $\mathrm{C}$ (with $R>10 \mathrm{~mm} \mathrm{~h}^{-1}$ ) precipitation, $\Lambda$ is quite constant (it is slightly lower), while $\mathrm{N}_{0}$ increases by $2-3$ orders of magnitude. Therefore, it is suggested that a $\mathrm{N}_{0}-\Lambda$ plot can be used as a $\mathrm{C} / \mathrm{S}$ discrimination, in which the shallow $\mathrm{C}$ and heavy $\mathrm{S}$ spectra (with $R$ between $2-10 \mathrm{~mm} \mathrm{~h}^{-1}$ ) fall in the middle of the other two categories. A good discriminator between $\mathrm{C} / \mathrm{S}$ spectra it is found to be the line:

$\Lambda+4.17=1.92 \log N_{0}$

which works well for all the Italian databases. Here, only the results for the Florence site, taken as representative (Fig. 2b), are considered.

\section{$4.3 \quad Z-R$ relationship}

The relationship between $Z$ and $R$ is generally a power law of the form: $Z=A R^{b}$, with $R$ in $\mathrm{mm} \mathrm{h}^{-1}$ and $Z$ in $\mathrm{mm}^{6} \mathrm{~m}^{-3}$. This relationship is very important in radar meteorology, the two coefficients A and b reflecting the type of rainfall (e.g. S or C). Generally high A values associated with low b values are representative of $\mathrm{C}$ mid-latitude precipitation (F: Fujiwara, 1956; J: Jones, 1956; Joss and Waldvogel, 1969). Moreover, the coefficient A is proportional to the average mean equivolumetric diameter $D_{0}$ for the considered period, while high b values reflect a greater variation of $D_{0}$.

Table 3 summarizes the $Z-R$ relationships for each database, computed by a linear regression method of $10 \log Z$ versus $\log R(\log Z=A+b \log R)$.

Generally, a good agreement is found between theory and past works on mid-latitude continental precipitation (e.g. the ones cited above: JW, J and F reporting $A=250,310,200$ - $b=1.5,1.25,1.45$ respectively for widespread/stratiform rain and $A=500,480,450-b=1.5,1.35,1.45$ for thunderstorm/convective rain), while marked differences are found when comparing the $Z-R$ relationships with the tropical ones found by TS, reporting $Z=139 R^{1.43}$ for $C$ cases, $Z=367 R^{1.30}$ for $\mathrm{S}$ cases and $Z=315 R^{1.20}$ for all cases. For all the Italian databases $A_{\mathrm{CONV}}>A_{\mathrm{STRAT}}$ (e.g. for the Ferrara cases $Z=704 R^{1.29}$ is found for the $\mathrm{C}$ cases, $Z=281 R^{1.35}$ for the $\mathrm{S}$ ones). In addition, the $Z-R$ relationships found here are generally not far from the MP one $Z=200 R^{1.6}$ found for widespread mid-latitude rain. It can also be noted that there are no significant variations passing from one Italian station to another.

\section{Conclusions and future work}

The analysis that was performed has allowed the microphysical characterization of precipitation occurring in Italy and

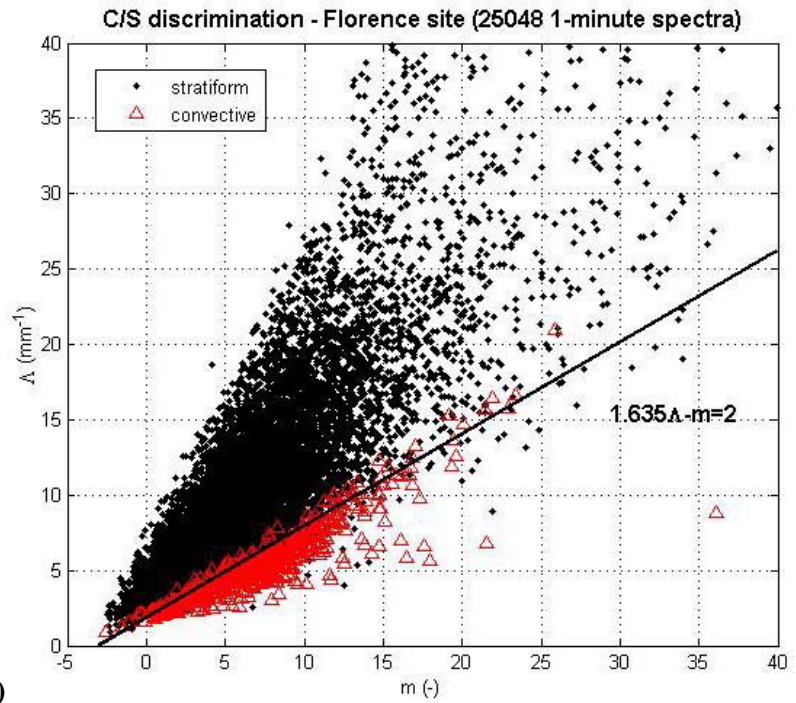

(a)
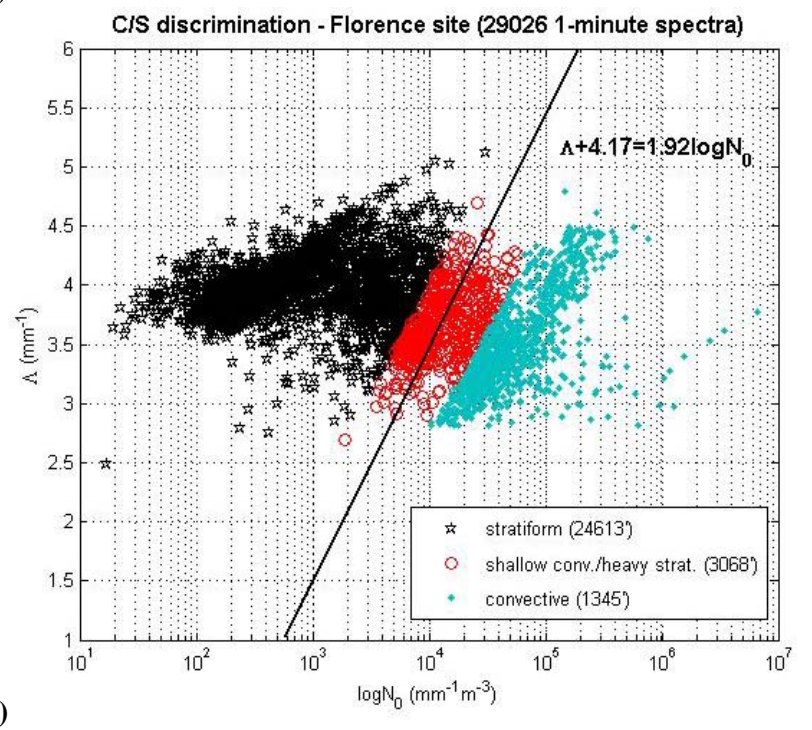

Fig. 2. Relationship between $\Lambda\left(\mathrm{mm}^{-1}\right)$ and $\mathrm{m}(-)$ for the Florence database using the JW disdrometer. The triangles are $\mathrm{C} 1$ minute spectra, the dots S 1-minute spectra. The solid line represents the proposed C/S discrimination (a); relationship between $\mathrm{N}_{0}$ $\left(\mathrm{mm}^{-1} \mathrm{~m}^{-3}\right)$ and $\Lambda\left(\mathrm{mm}^{-1}\right)$ for the Florence database using the Pludix disdrometer. The dots are C 1-minute spectra, the stars S 1-minute spectra, circles 1-minute shallowC/heavyS spectra. The solid line represents the proposed C/S discrimination (b). The different spectra are discriminated by using thresholds in rainfall rate and/or reflectivity values.

the discrimination between $\mathrm{C}$ and $\mathrm{S}$ rain, given an almost total lack of studies at mid-latitudes. Two different types of disdrometers were used: the classical JW disdrometer and a recent device called Pludix. A high number of different rain episodes were collected, allowing the creation of the most comprehensive database collected in Italy. A global microphysical analysis was performed by computing the $Z-R$ 
Table 3. The $A$ and $b$ parameters of the $Z=A R^{b}$ relationships $\left(Z\right.$ in $\mathrm{mm}^{6} \mathrm{~m}^{-3}$ and $R$ in $\mathrm{mmh}^{-1}$ ) for each database computed by a linear regression method.

\begin{tabular}{lll}
\hline Location & Intercept A & Exponent b \\
\hline Ferrara (JW) & 273 & 1.48 \\
Bologna (Pludix) & 316 & 0.95 \\
Florence (JW and Pludix) & 234263 & 1.341 .02 \\
Turin (Pludix) & 277 & 1.01 \\
South Italy Licata Surigheddu Rotondella (Pludix) & 259257269206 & 0.901 .021 .500 .84 \\
\hline
\end{tabular}

relationships, observing the average DSDs and DSD parameters for rain categories, and applying two C/S discrimination algorithms.

The results can be summarized as follows:

1. the rain distribution in Italy is well described by a gamma DSD (a better fit when using the JW disdrometer), and only in some cases (especially light rains) by an exponential DSD (a better fit when using Pludix data). The average DSD parameters for rain classes are in agreement with classical values and there are no marked differences passing form one station to another in Italy;

2. the classical $\mathrm{C} / \mathrm{S}$ discrimination algorithms fail at these latitudes (e.g. the tropical TS). A new C/S discrimination algorithm using Pludix data was implemented, based on parameters of an exponential DSD fitting the observed DSD. The previous C/S discrimination algorithm based on a gamma DSD using JW data (Caracciolo et al., 2006a) was refined. It is important to note that the $\mathrm{C} / \mathrm{S}$ discrimination methods based on disdrometric data are useful for discriminating between weak $\mathrm{S}$ and strong $\mathrm{C}$ rains. However, they have to be used in combination with polarimetric radar data in the $2<R<10 \mathrm{~mm} / \mathrm{h}$ range (of difficult interpretation, as suggested by many authors, e.g. TS), in which shallow $\mathrm{C}$ and heavy $\mathrm{S}$ rain can occur.

3. agreement with past works at mid-latitudes in Z-R relationships. There are no significant variations passing from one Italian station to another;

4. strong differences are observed in DSD parameters and $\mathrm{Z}-\mathrm{R}$ relationships on passing from $\mathrm{C}$ to $\mathrm{S}$ episodes.

The use of the disdrometers in the area covered by a multiparametric radar for calibration purposes is suggested and will be implemented in the near future, while radar data might systematically help in C/S discrimination.

Acknowledgements. We acknowledge S. Orlandini, A. Dalla Marta, and M. Napoli of the Department of Agronomy and Land Management, University of Florence, for their help in the JW and Pludix disdrometer installation and data management at the Montepaldi (Florence) site. We also acknowledge A. Piano of the University of Turin for providing the Pludix data.

A part of this work was carried out in the frame of the RIADE (Ricerca Integrata per l'Applicazione di tecnologie e processi innovativi per la lotta alla DEsertificazione) project and of the PRIN 2005 ("Indici di impatto idrometeorico e vulnerabilità del terreno") project.

Edited by: S. C. Michaelides

Reviewed by: two anonymous referees

\section{References}

Caracciolo C., Prodi, F., Battaglia, A., and Porcù, F.: Analysis of the moments and parameters of a gamma DSD to infer precipitation properties: a convective stratiform discrimination algorithm, Atm. Res., 80(2-3), 165-186, 2006a.

Caracciolo C., Prodi, F., and Uijlenhoet, R.: Comparison between Pludix and impact/optical disdrometers during rainfall measurement campaigns, Atm. Res., 82(1-4), 137-163, 2006 b.

Caracciolo C., Prodi, F., and Casazza, M.: Atmospheric precipitation analysis using both disdrometric and satellite data for desertification studies, Proc. ERAD Conference 2006, 191-194, 2006c.

Doviak, R. J. and Zrnic, D. S.: Doppler radar and weather observations, Academic Press, California, 1993.

Fujiwara, M.: Raindrop size distribution from individual storms, J. Atmos. Sci., 22, 585-591, 1965.

Jones, D. M. A.: Rainfall drop size distribution and radar reflectivity, Rep. No. 6, Illinois State Water Survey, Urbana, IL, 20 pp., 1956.

Joss, J. and Waldvogel, A.: Ein Spektrograph fuer Niederschlagstropfen mit automatischer Auswertung, Pure Appl. Geophys., 68, 240-246, 1967.

Joss, J. and Waldvogel, A.: Raindrop size distribution and sampling size errors, J. Atmos. Sci., 26, 566-569, 1969.

Krajewski W. F., Kruger, A., Caracciolo, C., Golé, P., Barthes, L., Creutin, J.-D., Delahaye, J.-Y., Nikolopoulos, E. I., Ogden, F., Vinson, J.-P.: DEVEX-Disdrometer Evaluation Experiment: Basic results and implications for hydrologic studies, Adv. in Water Res., 29, 311-325, 2006.

Marshall, J. S. and Palmer, W. M.: The distribution of raindrops with size, J. Meteor., 5, 165-166, 1948. 
Prodi, F., A. Tagliavini, F. Pasqualucci: Time variability in rainfall events observed by Pludix, Phys. Chem. Earth (B), 25(10-12), 959-963, 2000.

Testud J., Oury, S., Blank, R. A., Amayenc, P., Dou, X.: The concept of "Normalized" distribution to describe raindrop spectra: a tool for cloud physics and cloud remote sensing, J. Appl. Met., 40, 1118-1140, 2001.

Tokay, A. and Short, D.: Evidence from tropical raindrop spectra of the origin of rain from stratiform versus convective, J. Appl. Meteor., 35, 355-371, 1996.

Ulbrich, C.: Natural Variations in the analytical form of the raindrop size distribution, J. Clim. and Appl. Meterol., 22, 1764-1775, 1983.
Waldvogel, A.: The $\mathrm{N}_{0}$ jump of raindrop spectra, J. Atmos. Sci., 31, 1067-1078, 1974.

Wolff D. B., Marks, D. A., Amitai, E., Silberstein, D. S., Fisher, B. L., Tokay, A., Wang, J., and Pippitt, J. L.: Ground validation for the Tropical Rainfall Measuring Mission (TRMM), J. Atmos. Ocean. Technol., 22, 365-380, 2005.

Zawadski I., Monteiro, E., and Fabry, F.: The development of drop size distributions in light rain, J. Atm. Sci., 51, 1100-1113, 1994. 